\title{
Spectroelectrochemical characterisation of copper salen-based polymer-modified electrodes
}

\author{
Magda Martins ${ }^{\text {a }}$, Miguel Vilas Boas ${ }^{\mathrm{a}, 1}$, Baltazar de Castro ${ }^{\mathrm{a}}$, \\ A. Robert Hillman ${ }^{b, 2}$, Cristina Freire ${ }^{a, *, 2}$ \\ ${ }^{a}$ REQUIMTE/Departamento de Química, Faculdade de Ciências, Universidade do Porto, Rua do Campo Alegre, 687, 4169-007 Porto, Portugal \\ ${ }^{\mathrm{b}}$ Department of Chemistry, University of Leicester, Leicester LE1 7RH, UK
}

Received 4 February 2005; received in revised form 22 April 2005; accepted 23 April 2005

Available online 4 June 2005

\begin{abstract}
Electrogenerated polymers based on copper salen-type complexes were characterised electrochemically and by in situ UV-vis and ex situ EPR spectroscopy. The films, poly[Cu(salen)] and poly[Cu(saltMe)], exhibit reversible oxidative electrochemical behaviour in a wide potential range $(0.0-1.5 \mathrm{~V})$. Different regimes for charge transport behaviour are accessed by manipulation of film thickness and experimental time scale: thin films (surface concentration, $\Gamma<\mathrm{ca} .80 \mathrm{nmol} \mathrm{cm}{ }^{-2}$ ) show thin-layer/surface behaviour in the scan rate range used $\left(0.020-2.0 \mathrm{~V} \mathrm{~s}^{-1}\right)$, whereas thicker polymers $\left(\Gamma>\mathrm{ca} .90 \mathrm{nmol} \mathrm{cm}{ }^{-2}\right)$ exhibit a changeover from thin-layer to diffusion control regime at a critical scan rate that depends on polymer and film thickness: $0.15-0.20 \mathrm{~V} \mathrm{~s}^{-1}$ for poly[Cu(salen)], $90<\Gamma<130 \mathrm{nmol} \mathrm{cm}^{-2}$ and $0.20-0.30 \mathrm{~V} \mathrm{~s}-1$ for poly[Cu(saltMe)], $170<\Gamma<230 \mathrm{nmol} \mathrm{cm}^{-2}$.

UV-vis and EPR spectroscopies have allowed the characterisation of electronic states in the reduced and oxidised forms. The role of the copper atom during film oxidation was probed by combining UV-vis data with EPR on copolymers of the copper and nickel complexes. Data from both techniques are consistent and indicate that polymerisation and redox switching are associated with ligand-based processes. EPR of Ni-doped $\mathrm{Cu}$ polymers provided evidence for the non-involvement of the metal centre in polymer oxidation; like the analogous nickel polymers, copper polymers behave like delocalised $\pi$-system ('conducting') rather than discrete site ('redox') polymers.
\end{abstract}

(C) 2005 Elsevier Ltd. All rights reserved.

Keywords: Conducting polymers; Polymerisation; Cyclic voltammetry; EPR spectroscopy; UV-vis spectroscopy

\section{Introduction}

Preparation and characterisation of metal salen-based electroactive polymers is an active field of research due to their potential application as electrocatalysts, chemical sensors or optical devices. We have electrosynthesised several nickel salen-based polymers and we have used cyclic voltammetry and chronoamperometry to study film redox activity and charge transport [1-3], UV-vis, FT-IR and EPR spec-

\footnotetext{
* Corresponding author. Tel.: +35122 6082890; fax: +351 226082959 .

E-mail address: acfreire@ @fc.up.pt (C. Freire).

${ }^{1}$ Permanent address: Escola Superior Agrária de Bragança, 5301-855 Bragança, Portugal.

2 ISE member.
}

troscopies to explore aspects of polymer electronic structure $[1,4]$, and the electrochemical quartz crystal microbalance (EQCM) and probe beam deflection (PBD) to characterise ion and solvent transfer processes driven by redox switching [3,5], One important aspect that has emerged from the results is that the nickel centre is not involved in polymer oxidation: the polymer is best described as a polyphenylene-type compound (a "conducting polymer"), rather than an aggregation of discrete electroactive nickel complexes. The role of the nickel centre is to define the nature of the bridge between the biphenylene moieties in the ligand.

To extend our studies in this field, we have decided to pursue the electropolymerisation and characterisation of new polymers using different metal centres. With these studies, we will be able to evaluate the rather less obvious (see 


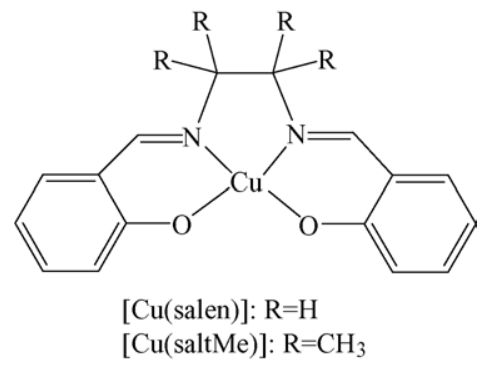

Scheme 1. Molecular structure of $[\mathrm{Cu}($ salen $)]$ and $[\mathrm{Cu}(\mathrm{saltMe})]$.

above) role of the metal in defining the polymer stability, electronic structure and charge conduction mechanism. We started with copper, a first row transition metal cation with similar chemical properties to nickel when complexed to salen-type ligands; furthermore, some polymers based on $[\mathrm{Cu}($ salen $)]$ monomers have already been prepared and their preliminary characterisation [6-10] showed great similarities to those of [Ni(salen)]-based polymers.

We have carried out a spectroelectrochemical characterisation of copper polymers with the same ligands we have used for nickel salen-based polymers. Herein, we report the results for polymers prepared by polymerisation of [Cu(salen)] and [Cu(saltMe)] (Scheme 1) in $0.1 \mathrm{~mol} \mathrm{dm}^{-3}$ TEAP/ $/ \mathrm{CH}_{3} \mathrm{CN}$. The polymers were deposited and characterised electrochemically by cyclic voltammetry and their electronic structures in the reduced and oxidised states were characterised by electronic and EPR spectroscopies. The spectroelectrochemical data reveal that oxidative polymerisation of copper salen-based monomers and redox switching of the corresponding polymers are ultimately ligand-based processes, as for their nickel analogs. The non-occurrence of a $\mathrm{Cu}(\mathrm{II}) / \mathrm{Cu}(\mathrm{III})$ redox process within polymer oxidation processes is illustrated by the similarity between the electronic bands of the oxidised copper and nickel polymers, and by EPR spectra of nickel/copper copolymers which show a radical-type signal superimposed on the $\mathrm{Cu}(\mathrm{II})$-derived anisotropic signal. However, copper has been shown to have a significant influence in the definition of the energies of band gap and related electronic states, which can ultimately determine the polymer semi-conductor properties.

\section{Results and discussion}

\subsection{Electrochemical polymerisation and redox switching}

\subsubsection{Polymerisation}

Cyclic voltammograms in $0.1 \mathrm{~mol} \mathrm{dm}^{-3} \mathrm{TEAP} / \mathrm{CH}_{3} \mathrm{CN}$ of $[\mathrm{Cu}($ salen $)]$ and $[\mathrm{Cu}$ (saltMe) $]$ monomers are very similar and resemble those observed for solutions of nickel complexes with the same ligands $[1,3]$. They are typical of irre-

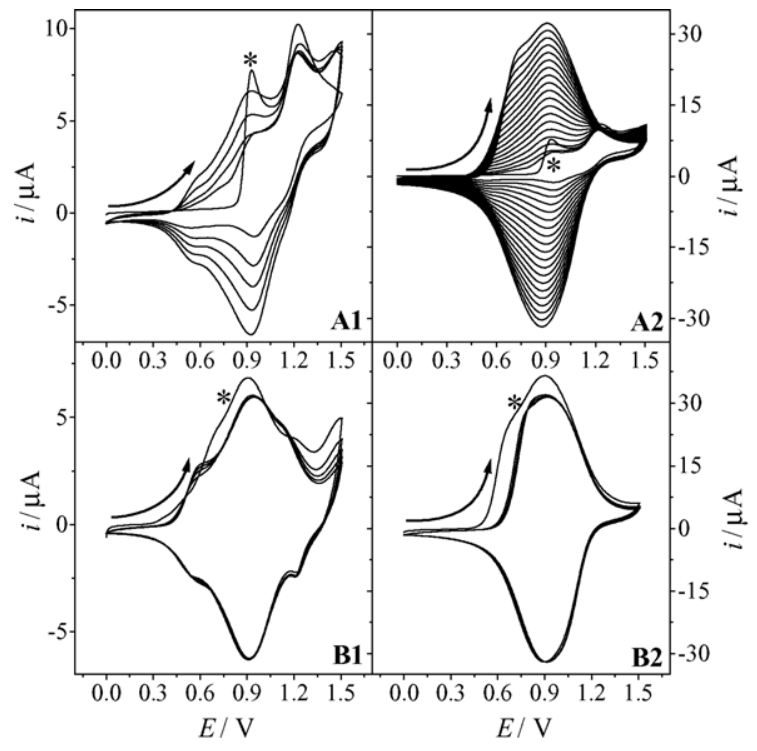

Fig. 1. Series of sequential cyclic voltammograms for anodic polymerisation of $1 \mathrm{mmol} \mathrm{dm}^{-3}[\mathrm{Cu}(\mathrm{saltMe})] / 0.1 \mathrm{~mol} \mathrm{dm}{ }^{-3} \mathrm{TEAP} / \mathrm{CH}_{3} \mathrm{CN}$ at a Pt disk electrode, between 0.0 and $1.5 \mathrm{~V}$ for: five (panel A1) and 20 (panel A2) polymerisation scans. Subsequent cyclic voltammograms $\left(v=0.100 \mathrm{~V} \mathrm{~s}^{-1}\right)$ for the same modified electrodes in monomer-free solutions, panels B1 and B2, respectively. Asterisk shows the first scan.

versible systems, showing a continuous increase in current intensity with the number of scan cycles, which reflects the accumulative electrosynthesis of an electroactive polymer. In Fig. 1 (panel A), a series of sequential voltammograms of $[\mathrm{Cu}(\mathrm{saltMe})]$ in $0.1 \mathrm{~mol} \mathrm{dm}^{-3} \mathrm{TEAP} / \mathrm{CH}_{3} \mathrm{CN}$ solution is depicted.

The first scan is different from the subsequent ones, and shows two well-defined anodic peaks at 0.93 and $1.23 \mathrm{~V}$ for $[\mathrm{Cu}(\mathrm{saltMe})]$ and at 0.92 and $1.17 \mathrm{~V}$ for [Cu(salen)]; the cathodic processes consist of low intensity waves at 0.70 and ca. $0.55 \mathrm{~V}$ for $[\mathrm{Cu}($ salen) $]$ and ca. 0.6 and $0.96 \mathrm{~V}$ $[\mathrm{Cu}(\mathrm{saltMe})]$.

After the first cycle, a new anodic broad-shaped peak appears at ca. $0.6 \mathrm{~V}$ for both polymers. Together with the waves at 0.92 or $0.93 \mathrm{~V}$, they grow continuously with the number of polymerisation cycles. Both for poly[Cu(salen)] and poly[Cu(saltMe)], the peak at $0.6 \mathrm{~V}$ shifts slightly towards more positive potentials after each consecutive cycle, until it merges with the most intense anodic peak, at 0.92 and $0.93 \mathrm{~V}$ for $[\mathrm{Cu}($ salen $)]$ and $[\mathrm{Cu}($ saltMe $)]$, respectively. For [Cu(salen)], the two peaks fuse after 20 scans of polymerisation, whereas for $[\mathrm{Cu}($ saltMe $)]$ it takes 30 scans.

Peak current intensities at $\nu=0.1 \mathrm{~V} \mathrm{~s}^{-1}$ during polymerisation cease to increase after about 30 polymerisation scans for poly[Cu(salen)], and about 60 scans for poly $[\mathrm{Cu}(\mathrm{saltMe})]$, and then slowly start to decrease. Visual inspection of the working electrode after cycling in monomer solution shows that both monomers form a green insoluble film on the $\mathrm{Pt}$ surface. 


\subsubsection{Redox switching}

Upon transferring the polymer-coated electrodes to a monomer-free $\mathrm{TEAP} / \mathrm{CH}_{3} \mathrm{CN}$ solution, we observe that the films show an electrochemical response (depicted in Fig. 1, panel B) similar to that for poly[Ni(saltMe)]. The films are moderately stable; cycling on a time scale of $12 \mathrm{~h}$ results in almost complete loss of electroactivity, but with poly[Cu(saltMe)] being significantly more stable than poly[Cu(salen)]. Copper polymers are less stable than the analogous nickel polymers, notably poly[Ni(saltMe)], which exhibits a remarkably high electrochemical stability $[2,3]$. Loss of electroactivity is not accompanied by visual loss of material deposited at the electrode surface. This prompts the hypothesis that the loss of electroactivity is due to polymer degradation; evidence in support of this idea will be presented later in the paper.

In the cyclic voltammograms of copper polymer-modified electrodes (Fig. 1, panels B1 and B2) the first scan is always different from the subsequent scans. This is a commonly reported feature of many conducting polymers [11] including the analogous nickel films [2,5,12]. The difference is more pronounced for thin polymers obtained after one to five potential cycles, and has been attributed to structural reorganisation processes in the as-grown polymers.

Excluding the first scan of redox switching, poly$[\mathrm{Cu}$ (salen)] shows two anodic processes, which are clearly observed in films prepared by up to five polymerisation scans, at $E_{1 / 2}(\mathrm{I})=0.6 \mathrm{~V}$ and $E_{1 / 2}(\mathrm{II})=0.90 \mathrm{~V}$. For films prepared with more than five cycles, only one wave is observed at $E_{1 / 2}=0.93 \mathrm{~V}$ (probably both processes occur, but we only see one wave). Similar behaviour is observed for poly[Cu(saltMe)]; for films prepared with 1-10 cycles, three processes $\left(E_{1 / 2}(\mathrm{I})=0.54-0.64 \mathrm{~V}, E_{1 / 2}(\mathrm{II})=0.94 \mathrm{~V}\right.$ and $E_{1 / 2}(\mathrm{III})=1.2 \mathrm{~V}$ ) are observed (see Fig. 1, panel B1) and for thicker polymers (prepared using 60 polymerisation scans), only one wave is observed at $E_{1 / 2}=0.93 \mathrm{~V}$ (see Fig. 1, panel B2).

\subsubsection{Coulometry}

By using the approach proposed in previous studies on poly[Ni(salen)]-based polymers [1-3], we can consider, as a first approximation, that three processes may contribute to the overall charge passed during a polymerisation scan: polymerisation and the two limiting situations for oxidation, a ligand-based redox process, and a metal-based redox process. The number of electrons per monomer unit associated with each process is: 2 electrons (and 2 protons) for polymerisation, $z$ electrons for copper-based redox switching (with the constraint that $z=0$ or 1) and $2 y$ electrons for the ligandbased redox switching ( $y$ electrons per phenyl ring). The ratio of the anodic charge passed in the polymerisation/deposition $\left(Q_{\text {pol }}\right)$ to that in oxidative redox switching $\left(Q_{\text {redox }}\right)$ is given by $Q_{\text {pol }} / Q_{\text {redox }}=(2+2 y+z) /(2 y+z)$.

Applying this equation to our data, we found that only by considering $z=0$ (no metal oxidation) was it possible to obtain physically meaningful solutions: for poly[Cu(salen)] we found $y=0.15 \pm 0.01$ and $n=0.30$ (doping level $n=2 y$ ), and for poly[Cu(saltMe) $] y=0.14 \pm 0.01$ and $n=0.28$. These results are consistent with ligand-based oxidation processes for both copper polymers, with approximately one charge delocalised over four monomer units. Apparently, copper salen-based polymers, like their nickel analogs, behave as 'conducting' polymers rather than 'redox' polymers; however, confirmation of this via spectroscopic evidence is needed and is given below.

\subsubsection{Effect of coverage}

Values of $\Gamma$ were plotted as a function of the number of electropolymerisation cycles. For poly[Cu(salen)], $\Gamma$ was found to increase linearly until the 10th polymerisation scan, after which $\Gamma$ increases more slowly until the 30th scan. Poly[Cu(saltMe)] exhibits a similar $\Gamma$ versus number of polymerisation scans profile, but with $\Gamma$ increasing linearly until the 30th polymerisation scan. This plateau-type behaviour has been observed for some of the analogous nickel salenbased polymers $[1,13]$ and redox polymers $[14,15]$. We stress that $\Gamma$ represents the accessible (not necessarily the total) number of redox sites on the time scale chosen; this value is controlled by charge transport, e.g. counter-ion transport. These results suggest that charge transport is faster through poly $[\mathrm{Cu}(\mathrm{saltMe})]$ than poly[Cu(salen) $]$.

\subsection{Cyclic voltammetric studies of film dynamics}

In Fig. 2 we show the voltammetric responses of poly[Cu(salen)], prepared with five $\left(\Gamma=52 \mathrm{nmol} \mathrm{cm}^{-2}\right.$,

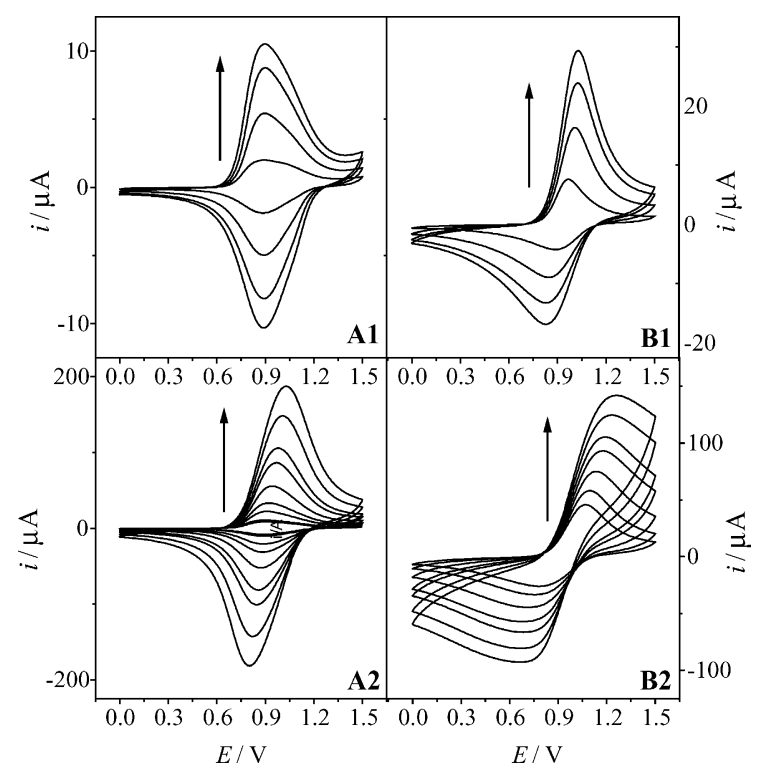

Fig. 2. Voltammetric responses of poly[Cu(salen)]-modified electrodes in $0.1 \mathrm{~mol} \mathrm{dm}{ }^{-3} \mathrm{TEAP} / \mathrm{CH}_{3} \mathrm{CN}$, between 0.0 and $1.5 \mathrm{~V}$ prepared with: (A1-A2) five $\left(\Gamma=52 \mathrm{nmol} \mathrm{cm}^{-2}\right)$ and (B1-B2) 20 polymerisation scans $\left(\Gamma=130 \mathrm{nmol} \mathrm{cm}^{-2}\right)$, for scan rates in the range $0.02-2.0 \mathrm{~V} \mathrm{~s}^{-1}$. Panels A1 and $\mathrm{B} 1$ correspond to $v=0.02,0.05,0.08$ and $0.1 \mathrm{~V} \mathrm{~s}^{-1}$; panels A2 and $\mathrm{B} 2$ correspond to $v=0.2,0.3,0.5,0.8,1,1.5$ and $2 \mathrm{~V} \mathrm{~s}^{-1}$. Arrows indicate increasing scan rate. 


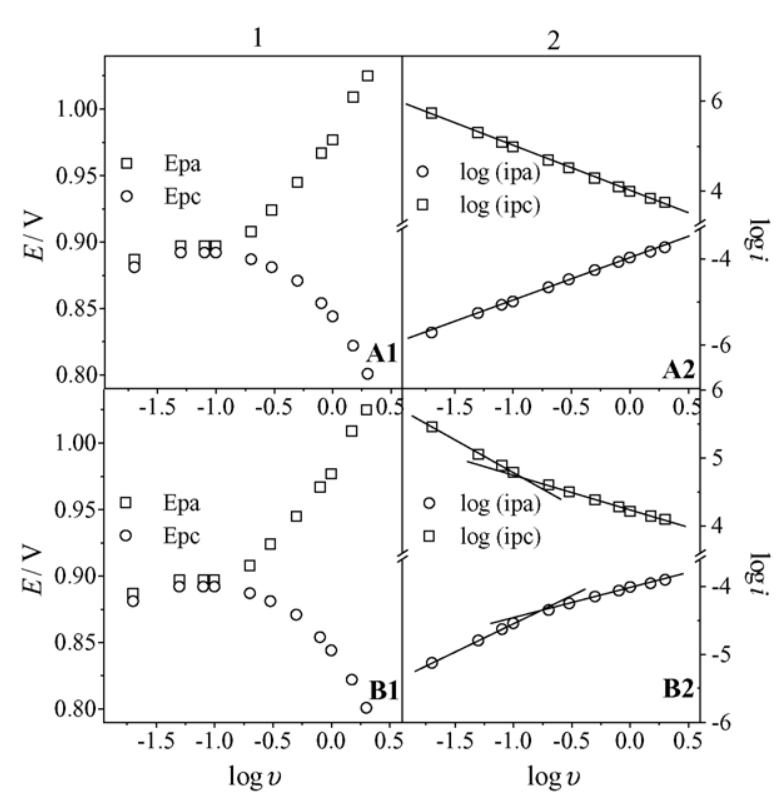

Fig. 3. Plots of $E_{\mathrm{a}}$ and $E_{\mathrm{c}}$ vs. $\log v$ (panel 1) and plots of $\log \left(i_{\mathrm{pa}}\right)$ and $\log \left(i_{\mathrm{pc}}\right)$ vs. $\log v$ (panel 2) for poly[Cu(salen)]-modified electrodes of Fig. $2 \mathrm{~A}$ $\Gamma=52 \mathrm{nmol} \mathrm{cm}^{-2}$ and (B) $\Gamma=130 \mathrm{nmol} \mathrm{cm}^{-2}$.

panel A) and with $20\left(\Gamma=130 \mathrm{nmol} \mathrm{cm}^{-2}\right.$, panel B) polymerisation scans, for scan rates in the range $0.02-2.0 \mathrm{~V} \mathrm{~s}^{-1}$. Two different types of behaviour are observed for the dependence of peak current and peak potential (most intense peak) with scan rate. For thin films, $\Gamma<52 \mathrm{nmol} \mathrm{cm}^{-2}$, and for all scan rates, a linear dependence of anodic and cathodic peak current on the scan rate is observed $(\log i$ versus $\log v$ plots have slopes close to unity; Fig. 3A2), which indicates a thin layer/surface-type regime for charge transport [16].

Strict adherence to this regime requires that the redox waves are symmetrically shaped, irrespective of the scan rate $\left(E_{\mathrm{pa}} \approx E_{\mathrm{pc}}\right)$, a feature that is not perfectly observed (Fig. 3A1). This can be ascribed to the observed coalescence of the peaks due the two redox processes at high scan rates that mask the peak potential of the most intense peak.

Thicker films $\left(\Gamma>91.3 \mathrm{nmol} \mathrm{cm}^{-2}\right)$ show, at slow scan rates $\left(v<0.29 \mathrm{~V} \mathrm{~s}^{-1}\right)$, voltammetric waves with characteristics similar to those described for thin films (Fig. 3B2). With increasing $v$, the voltammograms progressively acquire the characteristics of a diffusional system (note the "tailing" on current peaks), for which the diagnostic is a linear relationship between $i_{\mathrm{p}}$ and $v^{1 / 2}$ [16]. Plots of $\log i$ versus $\log v$ for thick films (Fig. 3B2) reveals that there is a critical scan rate for the anodic $\left(v_{\mathrm{a}}\right)$ and cathodic $\left(v_{\mathrm{c}}\right)$ processes, where the slope, $\mathrm{d}(\log i) / \mathrm{d}(\log v)$ decreases from 1 towards 0.5 . These results indicate a change from a thin-layer regime to a semiinfinite diffusion control. This transition between the two regimes has been observed for nickel and other polymermodified electrodes $[2,3,5,17,18]$ and as suggested by Bartlett [19], is determined by the interplay between scan rate and kinetics of charge transport throughout the film. Plots of $E_{\mathrm{p}}$ versus $\log v$ for thick polymers (Fig. 3B1) in the region where diffusion control is predominant $\left(v>v_{\mathrm{a}}, v_{\mathrm{c}}\right)$ show the anticipated increase in peak separation $(\Delta E)$.

Films of poly[Cu(saltMe)] show the same behaviour as those of poly[Cu(salen)]: diffusionless regime for thin films $\left(\Gamma<76.7 \mathrm{nmol} \mathrm{cm}^{-2}\right)$ and a mixed regime, shifting toward diffusional control, for thicker films $\left(\Gamma>172 \mathrm{nmol} \mathrm{cm}^{-2}\right)$. Data for the two polymers are summarised in Tables 1 and 2.

Under semi-infinite diffusion conditions, the peak current for a reversible electrode reaction is given by the Randles-Sevcik equation [20], which can be used to estimate the charge transport diffusion coefficient, $D_{\mathrm{CT}}$. For the work reported here, and for conditions where semi-infinite diffusion regime is observed, the product $D_{\mathrm{CT}}^{1 / 2} C$ was estimated from the plots of $i_{\mathrm{pa}}$ and $i_{\mathrm{pc}}$ versus $v^{1 / 2}$ for the two polymers; the respective values are summarised in Table 3. They are comparable to those observed for nickel homologous polymers $[1,2,5,13]$ and are in the range observed for other modified electrodes [21-23].

\subsection{In situ $U V$-vis spectroscopy}

The transmission spectra acquired during the first deposition cycle of $[\mathrm{Cu}($ salen $)]$ and $[\mathrm{Cu}($ saltMe $)]$ films by cycling the working electrode between 0.0 and $1.5 \mathrm{~V}$ are similar (Fig. S1, supplementary material exemplifies the observed behaviour for $[\mathrm{Cu}(\mathrm{saltMe})])$. There is a general increase in absorbance across the entire visible region for potentials higher than $0.9 \mathrm{~V}$ in the positive going scan, corresponding to the beginning of the oxidation. In particular, a new band at $475 \mathrm{~nm}$ is clearly observed whose intensity increases until $1.1 \mathrm{~V}$ on the negative going scan (beginning of the cathodic wave), and then starts to decrease. At the end of the cycle,

Table 1

Values of the slopes $\left(\mathrm{d} \log i_{\mathrm{p}} / \mathrm{d} \log v\right)$ for films of poly[Cu(salen)] prepared with different number of polymerisation scans

\begin{tabular}{|c|c|c|c|c|c|c|c|}
\hline \multirow[t]{3}{*}{ No. of scans } & \multirow[t]{3}{*}{$\Gamma\left(\mathrm{nmol} \mathrm{cm}^{-2}\right)$} & \multicolumn{6}{|c|}{ Slopes $\left(\mathrm{d} \log i_{\mathrm{p}} / \mathrm{d} \log v\right)$} \\
\hline & & \multicolumn{3}{|c|}{ Anodic } & \multicolumn{3}{|c|}{ Cathodic } \\
\hline & & Low $v$ & High $v$ & Break point $\left(\mathrm{V} \mathrm{s}^{-1}\right)$ & Low $v$ & $\operatorname{High} v$ & Break point $\left(\mathrm{V} \mathrm{s}^{-1}\right)$ \\
\hline 1 & 8.85 & 0.94 & - & - & 1.01 & - & - \\
\hline 3 & 27.0 & 0.99 & - & - & 1.03 & - & - \\
\hline 5 & 51.6 & 0.99 & - & - & 0.99 & - & - \\
\hline 10 & 91.4 & 1.01 & 0.70 & 0.15 & 0.94 & 0.74 & 0.23 \\
\hline 20 & 130 & 0.83 & 0.44 & 0.15 & 0.96 & 0.51 & 0.18 \\
\hline
\end{tabular}


Table 2

Values of the slopes $\left(\mathrm{d} \log i_{\mathrm{p}} / \mathrm{d} \log v\right)$ for films of poly[Cu(saltMe)] prepared with different number of polymerisation scans

\begin{tabular}{|c|c|c|c|c|c|c|c|}
\hline \multirow[t]{3}{*}{ No. of scans } & \multirow[t]{3}{*}{$\Gamma\left(\mathrm{nmol} \mathrm{cm}^{-2}\right)$} & \multicolumn{6}{|c|}{ Slopes $\left(\operatorname{dlog} i_{\mathrm{p}} / \mathrm{d} \log v\right)$} \\
\hline & & \multicolumn{3}{|c|}{ Anodic } & \multicolumn{3}{|c|}{ Cathodic } \\
\hline & & Low $v$ & High $v$ & Break point $\left(\mathrm{V} \mathrm{s}^{-1}\right)$ & Low $v$ & High $v$ & Break point $\left(\mathrm{V} \mathrm{s}^{-1}\right)$ \\
\hline 1 & 6.8 & 1.28 & - & - & 1.34 & - & - \\
\hline 3 & 30.6 & 1.22 & - & - & 1.26 & - & - \\
\hline 5 & 40.2 & 1.23 & - & - & 1.34 & - & - \\
\hline 10 & 76.8 & 1.06 & - & - & 1.03 & - & - \\
\hline 20 & 172 & 0.99 & 0.67 & 0.30 & 1.00 & 0.70 & 0.29 \\
\hline 30 & 215 & 0.93 & 0.43 & 0.19 & 0.86 & 0.41 & 0.24 \\
\hline 40 & 229 & 0.87 & 0.38 & 0.20 & 0.80 & 0.61 & 0.12 \\
\hline
\end{tabular}

there is a net increase in absorbance over the entire visible range, associated with film deposition.

After electrodeposition, the modified electrodes were transferred to monomer-free $\mathrm{CH}_{3} \mathrm{CN}$ solutions and electronic spectra collected at $0.1 \mathrm{~V}$ intervals. Both polymer films in the neutral state $(E=0.0 \mathrm{~V})$ have spectra similar to those of the corresponding monomers and are typical of $\mathrm{Cu}(\mathrm{II})$ compounds in a square planar geometry (Table 3). They show a broad medium intensity band at $\lambda=570 \mathrm{~nm}$ for $[\mathrm{Cu}$ (salen) $]$ and at $560 \mathrm{~nm}$ for [Cu(saltMe) $]$, assigned to the three unresolved $\mathrm{d}-\mathrm{d}$ electronic transitions $\left(\mathrm{d}_{y z} \leftarrow\left\{\mathrm{d}_{z^{2}} ;\left(\mathrm{d}_{x y}, \mathrm{~d}_{x z}\right)\right.\right.$ and $\left.\left.\mathrm{d}_{x^{2}}-\mathrm{d}_{y^{2}}\right\}\right)[24,25]$, and high intensity bands at $\lambda<430 \mathrm{~nm}$ due to $\mathrm{CT}$ and intra-ligand transitions. The similarity of the $\mathrm{d}-\mathrm{d}$ electronic bands between the monomer and polymer spectra provides an indication that the co-ordination sphere of copper remains unchanged upon polymerisation. Furthermore, the CT bands are red shifted on going from the monomer to the polymer, which is consistent with a high degree of conjugation in the polymers.

As the polymers are oxidised, the accumulated spectra for both polymers show an increase in intensity in the regions ca. 400,500 and $>820 \mathrm{~nm}$, and a decrease in absorbance for the region $\lambda<350 \mathrm{~nm}$, near to the lower limit of the instrumentation; the reverse behaviour occurs upon reduction. By depicting the latter spectra as difference spectra, referenced to that of the polymers in the neutral state (see Fig. 4A) demonstrated for poly $[\mathrm{Cu}(\mathrm{saltMe})]$ ), several electronic bands can be clearly observed above $0.5 \mathrm{~V}$ in the positive going scan for both polymers. We see a band with $\lambda_{\max }<315 \mathrm{~nm}$, a band with $\lambda_{\max }>820 \mathrm{~nm}$ (high-energy edge of a band extending

Table 3

Values of $D^{1 / 2} C$ obtained from cyclic voltammetry using the Randles-Sevcik equation for both polymers under diffusion-controlled regime

\begin{tabular}{lllll}
\hline Polymer & \multicolumn{4}{l}{$D^{1 / 2} C \times 10^{7}\left(\mathrm{~mol} \mathrm{~cm}^{-2} \mathrm{~s}^{-1 / 2}\right)$} \\
\cline { 2 - 5 } & No. of scans & $\Gamma\left(\mathrm{nmol} \mathrm{cm}^{-2}\right)$ & Anodic & Cathodic \\
\hline Poly[Cu(salen)] & 10 & 91.4 & 1.27 & 1.01 \\
& 20 & 120 & 0.63 & 0.46 \\
Poly[Cu(saltMe)] & 20 & 172 & 2.49 & 2.89 \\
& 30 & 215 & 1.54 & 0.96 \\
& 40 & 229 & 0.85 & 0.77 \\
\hline
\end{tabular}

into the near-IR) and bands at $\lambda=364$ (360), 484 (486); data in parentheses refer to poly[Cu(salen)].

In Fig. 5 (panels a-d), absorbance data from Fig. 4 are plotted as functions of applied potential. Three different patterns for band absorbance variation can be distinguished. (i) The bands at $\lambda_{\max }=364$ (360) and $\lambda>820 \mathrm{~nm}$ start to increase at $0.5 \mathrm{~V}$, reach a maximum around $1.0 \mathrm{~V}$ in the forward scan, and decrease thereafter until the positive potential limit $(1.5 \mathrm{~V})$; (ii) the band at $\lambda_{\max }=484(486) \mathrm{nm}$, that is
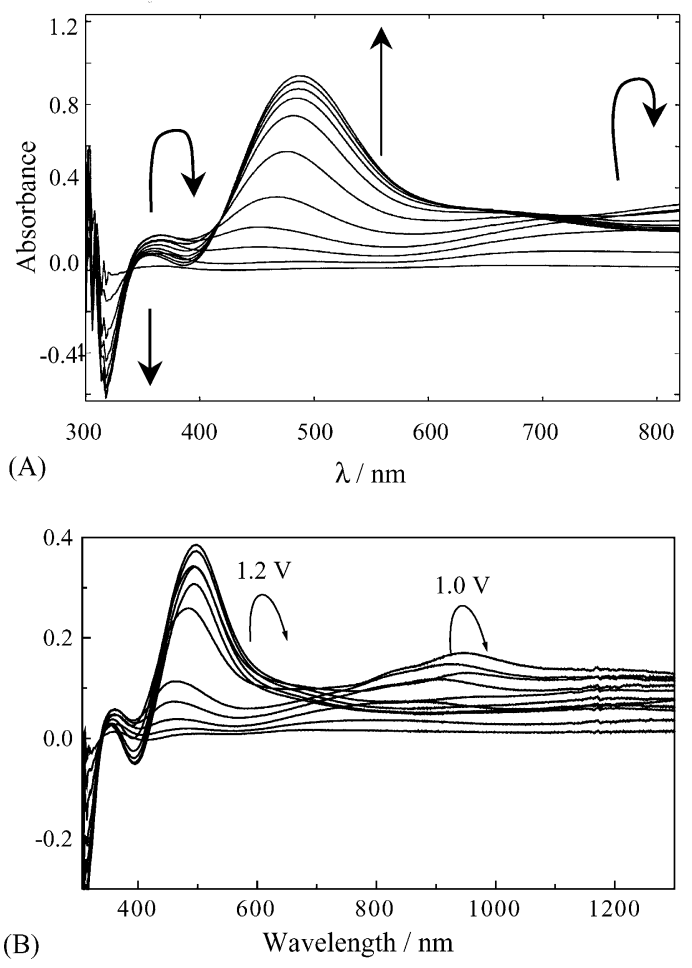

Fig. 4. UV-vis transmission spectra of a poly[Cu(saltMe)] coated electrode in $0.1 \mathrm{~mol} \mathrm{dm}^{-3} \mathrm{TEAP} / \mathrm{CH}_{3} \mathrm{CN}$ : (A) dynamic differential spectra (referenced to that of neutral polymer; collected while scanning the potential from 0 to $1.5 \mathrm{~V}$ at $0.1 \mathrm{~V}$ intervals; scan rate $0.01 \mathrm{~V} \mathrm{~s}^{-1}$ ) referenced to $0.1 \mathrm{~mol} \mathrm{dm}^{-3} \mathrm{TEAP} / \mathrm{CH}_{3} \mathrm{CN}, \lambda=300-820 \mathrm{~nm}$; (B) static differential spectra (referenced to that of neutral polymer; collected by holding the electrode potential at values from 0 to $1.5 \mathrm{~V}$ at $0.1 \mathrm{~V}$ intervals) referenced to $0.1 \mathrm{~mol} \mathrm{dm}^{-3} \mathrm{TEAP} / \mathrm{CH}_{3} \mathrm{CN}, \lambda=300-1300 \mathrm{~nm}$. Arrows indicate increasing potential. 


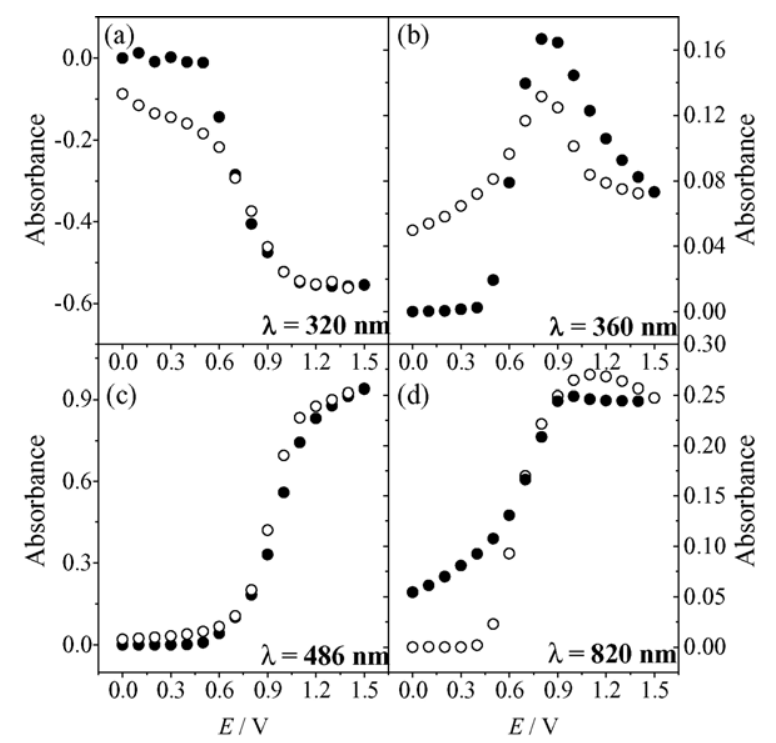

Fig. 5. Plots of the absorbance vs. $E$ of electronic bands of Fig. 4A for $\lambda_{\mathrm{m}}$ (a) 320 , (b) 360 , (c) 486 and (d) $820 \mathrm{~nm}$ acquired during the first scan in TEAP/CH $\mathrm{CH}_{3} \mathrm{CN}, v=0.01 \mathrm{~V} \mathrm{~s}^{-1}$. Symbols: $(\bullet)$ anodic scan; $(\bigcirc)$ cathodic scan.

much more intense than the others, increases from $0.65 \mathrm{~V}$ until $1.5 \mathrm{~V}$ (positive potential limit), but with a continuous red shift in $\lambda_{\max }(496 \mathrm{~nm}$ at $1.5 \mathrm{~V}$ ) and finally, (iii) the band at $\lambda_{\max }=320 \mathrm{~nm}$ decreases from $0.5 \mathrm{~V}$ and reaches a minimum near $1.3 \mathrm{~V}$. All absorbance variations with potential are chemically reversible but show minor hysteresis in dynamic experiments, suggesting some charge trapping, which can be released upon holding the potential constant at $0 \mathrm{~V}$ for a few seconds; this restores the absorbance values.

The electronic bands and their Abs versus $E$ profiles observed during copper polymer redox switching are similar to those observed for nickel polymer redox switching $[1,4]$, although shifted to higher energies. These similarities can be taken as an indication that charge conduction (and charge carriers) in both polymers are similar, i.e., we observe ligand-based processes during copper polymer electrochemistry.

Difference spectra obtained during subsequent scans exhibit the same electronic features as the spectra acquired during the first scan, but show a decrease in absorbance that parallels the decrease in current intensity observed in the cyclic voltammograms. Plots of Abs versus $E$ for the ninth scan (Fig. S2, supplementary material exemplifies this behaviour for poly $[\mathrm{Cu}(\mathrm{saltMe})]$ ), show in the forward scan a shift of the maximum absorbance to higher potentials and in the reverse scan a shift of the maximum absorbance toward lower potentials, leading to a very high degree of hysteresis in the plots. This suggests transport and/or kinetic limitations consequent upon continuous cycling, and reflects the moderate stability of copper polymers. After several hours of cycling, when no electrochemical response is detected, no redox-driven electronic band changes can be observed. Furthermore, the spectra of the electroinactive polymers in the reduced state $(0.0 \mathrm{~V})$ show the bands at $\lambda_{\max }=550$ and $310 \mathrm{~nm}$, but the band at $\lambda \approx 400 \mathrm{~nm}$ that was observed in the as-grown electroactive polymers has practically disappeared. We need to consider two possible causes for this: physical loss of polymer from the electrode surface and inactivation (but retention on the surface) of the polymer. The common feature associated with these two cases-which we see experimentally-is loss of potential-driven optical changes. The difference between them is that loss from the surface would result in disappearance of the (potential independent) absorbance, but retention on the surface with loss of electroactivity would result in the absolute absorbance being retained. The data are clearly only consistent with retention on the surface but progressive inactivation of the polymer. These irreversible changes in the polymer's electronic structure are manifested in the electronic spectra and its electron transfer properties.

In order to get information on the near-IR region electronic bands at $\lambda>800 \mathrm{~nm}$, we have used a spectrometer able to record spectra at longer wavelengths $(300-1600 \mathrm{~nm})$ (Fig. 4B). The scanning mode of this instrument required us to acquire static spectra at fixed potentials, instead of dynamically during potential cycling. The electronic spectra in the region $330-700 \mathrm{~nm}$ are identical to those observed when spectra were dynamically acquired during potential cycling, but using a wider spectral range it was possible to see beyond $\lambda=800 \mathrm{~nm}$; there are electronic transitions at $\lambda=965$, 710 (sh) $\mathrm{nm}$, for poly $[\mathrm{Cu}$ (salen) $]$ and $\lambda=945,840$ (sh) $\mathrm{nm}$ for $[\mathrm{Cu}($ saltMe $)]$.

The moderate electrochemical stability of copper polymers is clearly seen in the electronic spectra acquired potentiostatically. Plots of Abs versus $E$ (Fig. S3, supplementary material exemplifying this behaviour for poly $[\mathrm{Cu}(\mathrm{saltMe})]$ ) are similar to those of Fig. 5 only in the forward scan. In the subsequent reverse scan, the consequences of polymer degradation are seen in the significant decrease in absorbance; for this reason, extinction coefficients were calculated using only data acquired potentiodynamically, as described below.

By coupling coulometric data with the absorbance of the different bands for the redox switching in $\mathrm{CH}_{3} \mathrm{CN}$ (Fig. 5), it is possible to estimate the molar extinction coefficients, $\varepsilon(\lambda) / \mathrm{mol}^{-1} \mathrm{dm}^{3} \mathrm{~cm}^{-1}$, for each electronic band by using the equation: $A(\lambda)=\varepsilon(\lambda) Q / n F$ [26], where $F$ is the Faraday and $Q$ the charge. The results are depicted in Fig. 6 (panels a-d), exemplified for poly[Cu(saltMe)].

Estimates of the molar extinction coefficients for the electronic bands can be obtained from the slopes of straight-line regions in Fig. 6 where absorbance changes are maximal. Using the value $n=0.30$ for poly $[\mathrm{Cu}$ (salen) $]$ and $n=0.28$ for poly $[\mathrm{Cu}(\mathrm{saltMe})]$ for the number of electrons transferred per monomer unit (doping level) obtained from coulometric data, the molar extinction coefficients were calculated: $\varepsilon$-values (see Table 4) are in the range $1000-2900 \mathrm{~mol}^{-1} \mathrm{dm}^{3} \mathrm{~cm}^{-1}$. The $\varepsilon$-values are much higher than those expected for copper $\mathrm{d}-\mathrm{d}$ transitions and are typical of electronic transitions 


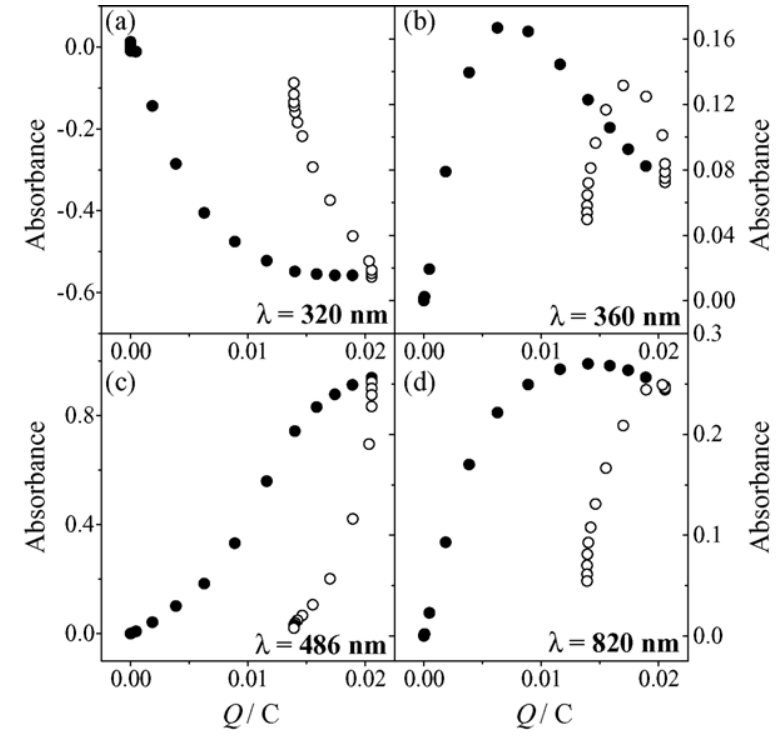

Fig. 6. Plots of the absorbance vs. $Q$ of electronic bands of Fig. 4A for $\lambda_{\mathrm{m}}$ (a) 320, (b) 360, (c) 486 and (d) $820 \mathrm{~nm}$ acquired during the first scan in TEAP/CH $\mathrm{CH}_{3} \mathrm{CN}, v=0.01 \mathrm{~V} \mathrm{~s}^{-1}$. Symbols: $(\bullet)$ anodic scan; $(\bigcirc)$ cathodic scan.

between states that have large contributions from ligandbased orbitals [24]. As these electronic bands are associated with the electroactivity of the polymers (and thus to charge carriers), we can conclude that polymer oxidation involves ligand-based processes. In order to get further information on the charge carriers responsible for the observed electronic transitions, EPR spectra were obtained.

\subsection{EPR spectroscopy}

The copper polymers obtained from potential controlled electrolysis of their monomers at different potentials (1.3 and $1.5 \mathrm{~V}$ ) show very broad isotropic EPR spectra with $g_{\text {iso }} \approx 2.12$ and 2.10 for poly[Cu(salen)] and $g_{\text {iso }} \approx 2.08$ and 2.09 for poly $[\mathrm{Cu}(\mathrm{saltMe})]$ at room temperature and $77 \mathrm{~K}$, respectively (see Fig. 7A for the example of poly[Cu(saltMe)]). The signal intensity increases with deposition time, and depends on temperature (although not explored in detail, the spectra are

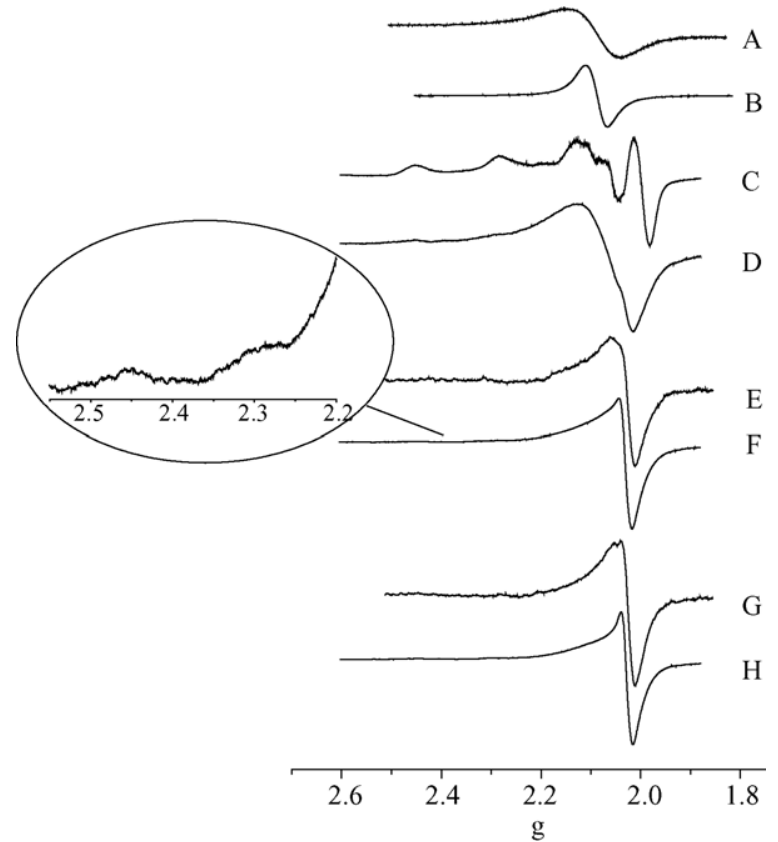

Fig. 7. Ex situ EPR spectra: (A) poly[Cu(saltMe)] in the oxidised state $(1.3 \mathrm{~V})$ at $\mathrm{rt}$; (B) powder $[\mathrm{Cu}($ saltMe) $]$ at $\mathrm{rt}$; (C) $[\mathrm{Cu}$ (saltMe) $]$ in $\mathrm{CH}_{3} \mathrm{CN}$ at $77 \mathrm{~K}$; (D) poly $\left[\mathrm{Cu}_{0.50} \mathrm{Ni}_{0.50}\right.$ (saltMe) $]$ at $77 \mathrm{~K}$ (obtained at $1.3 \mathrm{~V}$ ); (E) poly[ $\mathrm{Cu}_{0.25} \mathrm{Ni}_{0.75}$ (saltMe)] at $\mathrm{rt}$ (obtained at $1.3 \mathrm{~V}$ ); (F) poly $\left[\mathrm{Cu}_{0.25} \mathrm{Ni}_{0.75}\right.$ (saltMe)] at $77 \mathrm{~K}$ (obtained at $1.3 \mathrm{~V}$ ); $(\mathrm{G})$ poly $\left[\mathrm{Cu}_{0.25}-\right.$ $\mathrm{Ni}_{0.75}$ (saltMe) $]$ at rt (obtained at $\left.1.5 \mathrm{~V}\right) ;(\mathrm{H})$ poly $\left[\mathrm{Cu}_{0.25} \mathrm{Ni}_{0.75}(\mathrm{saltMe})\right]$ at $77 \mathrm{~K}$ (obtained at $1.5 \mathrm{~V}$ ).

much more intense at $77 \mathrm{~K}$ ). However, the applied potential (comparing data at 1.3 and $1.5 \mathrm{~V}$ ) had no detectable effect on the signal intensity.

The $g_{\text {iso }}$ values are much larger than those of organic radical species, are similar to those of copper monomers in powder samples (Fig. 7B) and taken together with the large peak-to-peak distance $(16.7 \mathrm{mT})$ suggest that the EPR signals of the oxidised polymers are mainly determined by copper(II) centers $[27,28]$. In this context, as there is no variation in signal intensity for the polymer with the applied potential, we can conclude that no oxidation of the metal centre is occurring during the oxidation of the polymer; oxidation of the metal centres to $\mathrm{Cu}(\mathrm{III})$ would result in a decrease in signal

Table 4

Electronic bands and molar extinction coefficients for copper monomers and respective polymers ${ }^{\mathrm{a}}$

\begin{tabular}{|c|c|c|c|c|}
\hline \multirow{2}{*}{$\frac{\text { Compound }}{[\mathrm{Cu}(\text { salen })]}$} & \multicolumn{4}{|c|}{$\lambda(\mathrm{nm}) / \varepsilon\left(\mathrm{mol}^{-1} \mathrm{dm}^{-3} \mathrm{~cm}^{-1}\right)$} \\
\hline & & $360(10100)$ & $383(6740)$ & $570(380)$ \\
\hline [Cu(saltMe)] & & $360(10100)$ & 379 (7710) & $560(320)$ \\
\hline Poly $[\mathrm{Cu}(\text { salen })]_{\text {red }}$ & $<300$ & 400 & & 550 \\
\hline Poly $[\mathrm{Cu}(\text { saltMe })]_{\text {red }}$ & $<300$ & 400 & & 570 \\
\hline Poly $[\mathrm{Cu}(\text { salen })]_{o x}{ }^{b}$ & $\begin{array}{l}<300 \\
316(1040)^{\mathrm{c}}\end{array}$ & $364(1860)$ & $484(2590)$ & $\begin{array}{l}>800 \\
820(1590)^{c}\end{array}$ \\
\hline Poly $[\mathrm{Cu}(\mathrm{saltMe})]_{\mathrm{ox}}{ }^{\mathrm{b}}$ & $\begin{array}{l}<300 \\
320(2820)^{\mathrm{c}}\end{array}$ & $360(1520)$ & $486(3400)$ & $\begin{array}{l}>800 \\
820(1870)^{\mathrm{c}}\end{array}$ \\
\hline
\end{tabular}

\footnotetext{
a Obtained in the Hewlett Packard HP8451A spectrometer in the range 300-820 nm.

$\mathrm{b}$ The molar extinction coefficients were calculated as described in the text.

c This wavelength corresponds to the maximum of the band which is available from the spectrum, see details in the text.
} 
intensity, as $\mathrm{Cu}(\mathrm{III})$ in square planar geometry $\left(\mathrm{d}^{8}\right.$ system) is EPR silent.

In order to further characterise the copper EPR signal in oxidised polymers, we decided to magnetically dilute the copper polymer by copolymerisation with the analogous nickel monomers. The results presented here refer only to the poly $[\mathrm{Cu}($ saltMe $)]$ polymers due to the low stability of poly $[\mathrm{Cu}($ salen $)]$.

Cyclic voltammograms for copolymerisation of $1: 1$ $[\mathrm{Cu}($ saltMe $)] /[\mathrm{Ni}($ saltMe $)]$ monomer solutions and redox switching (Fig. S4, supplementary material), show features due to nickel and copper monomers. The resulting copolymer prepared at $1.3 \mathrm{~V}$ (designated poly $\left[\mathrm{Cu}_{0.50} \mathrm{Ni}_{0.50}\right.$ (saltMe)]) shows an axial-type spectrum at $77 \mathrm{~K}$ that exhibits hyperfine couplings due to the interaction between the unpaired electron and the $\mathrm{Cu}(\mathrm{II})$ atom $\left({ }^{53} \mathrm{Cu}\right.$ and $\left.{ }^{53} \mathrm{Cu}, I=3 / 2\right)$ in the low magnetic field region. In the high magnetic field region, no hyperfine couplings were observed due to the low spectral resolution (Fig. 7D). The polymer spectrum shows EPR parameters in the low magnetic field region very similar to those observed for the corresponding monomer in a magnetically dilute medium $\left(\mathrm{CH}_{3} \mathrm{CN}\right.$ solution, Fig. $\left.7 \mathrm{C}\right)$, thus typical of $\mathrm{Cu}(\mathrm{II})$ with a $\left(\mathrm{d}_{x y}\right)^{1}$ ground state [27,28]: poly[Cu(saltMe)], $A_{\|}^{\mathrm{Cu}}=19.7 \mathrm{mT}, g_{\|}=2.23$ and $[\mathrm{Cu}($ saltMe $)], A_{\|}^{\mathrm{Cu}}=19.9 \mathrm{mT}$, $g_{\|}=2.21$. Essentially, when the $\mathrm{Cu}$ atoms are very distant there is no interaction and when they are rather close the interaction is sufficiently strong as to give very different spectra. Thus, there is only a narrow regime where $\mathrm{Cu}$ dimers are relevant and where the same spectra would result; consideration of the inter- and intra-molecular geometry shows that we are simply not in this regime, since $\mathrm{Cu}$ centres in the same polymer strand are too far away to interact, and interaction between two $\mathrm{Cu}$ centres from different strands are not predicted, particularly for the sterically-hindered saltMe ligand. The comparison of the two spectra in the high magnetic field region is not straightforward due to the lack of spectral resolution for the polymer; nevertheless, it can be seen that the hyperfine splitting observed in the monomer spectrum might correspond to the broad envelope in the polymer spectrum.

We have further diluted the polymer by using a solution with a higher concentration of nickel monomer, $1 \mathrm{Cu}: 3 \mathrm{Ni}$, in order to improve the resolution in the high magnetic field region. The room temperature EPR spectrum of the new copolymer, denoted as poly $\left[\mathrm{Cu}_{0.25} \mathrm{Ni}_{0.75}\right.$ (saltMe)], obtained at $1.3 \mathrm{~V}$ still shows the typical $\mathrm{Cu}$ (II) features in the parallel region, although with very low intensity, but in the perpendicular region two different signals can be seen, one due to copper (the perpendicular $\mathrm{Cu}$ signal) and the other a radicaltype signal, which has lower intensity than that of $\mathrm{Cu}$. At $77 \mathrm{~K}$, the two signals in the perpendicular region increase in intensity with that of the radical species showing the greater increase (Fig. 7E and F).

Moreover, if this radical signal corresponds to charge carriers (polarons), it would be dependent both on temperature and on potential. The same polymer prepared at $1.5 \mathrm{~V}$ exhibits EPR spectra similar to that obtained at $1.3 \mathrm{~V}$ : the two sig- nals in the perpendicular region (copper and radical) now show similar intensities at room temperature (the radical signal intensity has increased with applied potential) and at $77 \mathrm{~K}$ the radical signal is also the most intense signal (see Fig. 7G and $\mathrm{H}$ ). These results suggest that the radical signal must be due to charge carriers in the copolymers (polarons), but do not directly indicate with which - if any - metal centre it is associated.

The high magnetic dilution of copper in the copolymer EPR spectra, taken together with the observation that the individual monomer polymerisations involve ligand-based processes and occur at very similar potentials, led us to propose that these materials are genuine copolymers, not a blend of nickel and copper homopolymer strands. In this context, the radical EPR signal of the copolymers must be attributed to the charge carriers (polarons) within the copolymer and, consequently, are delocalised by nickel and copper centres. We can go further and make the reasonable speculation that charge conduction in pure copper polymers is similar to that of nickel polymers, i.e., is based on polarons; failure to detect them in the pure copper polymer spectra was due to the broad intense $\mathrm{Cu}$ (II) EPR signal, a consequence of the high concentration of $\mathrm{Cu}(\mathrm{II})$ centres within the polymer. No significant interaction between the copper unpaired spin $\left(\left(\mathrm{d}_{x y}\right)^{1}\right.$ ground state) and the unpaired spin from charge carriers $(\pi$ delocalised) is detected; this is probably due to their perpendicular orientations.

The absence of the interaction between the unpaired spin from the charge carriers and the metal spin density was also observed in the homologous ${ }^{61} \mathrm{Ni}(I=3 / 2)$ enriched polymers [4]. This behaviour contrasts with the results observed in the EPR characterisation of the monomeric oxidised species of copper(II) complexes with salen-type ligands where no polymerisation has occurred, due to the blocking of 3 and 5 position of the aldehyde moieties [29]. For these monomeric $\mathrm{Cu}$ systems, ligand-based oxidations were also observed which originated the formation of phenoxylbased mono- and di-radical $\mathrm{Cu}$ (II) species. However, these oxidised species exhibit EPR spectra compatible with strong interaction between $\mathrm{Cu}(\mathrm{II})$ unpaired spin and those from the phenoxyl radicals [29]. The disparate EPR behaviour between our $\mathrm{Cu}$ polymeric films and the monomeric radical $\mathrm{Cu}$ species is due to the localised nature of the latter ligand's unpaired spins, which contrast with the delocalised nature of the unpaired spin within the films induced by the extensive film $\pi$-delocalisation.

\subsection{Discussion: band structure}

On the basis of the EPR spectra, the main charge carriers are identified as polarons, allowing the electronic bands in the oxidised polymer to be assigned using the polaronic model [30]. In this model, there are three electronic features assigned to transitions involving states in the band gap generated during polymer oxidation [30]: $W_{1}$ from the valence band to the bonding polaron level, $W_{2}$ from the valence band 
to the anti-bonding polaron level and $W_{3}$ from the bonding to the anti-bonding polaron level. The energetics of these transitions are related to each other and to the intervalence band ( $W_{\mathrm{I}}$ ) as follows: $W_{1}+W_{3}=W_{2}$ and $W_{1}+W_{2}=W_{\mathrm{I}}$ (assuming, as commonly done, symmetrical distribution of the gap-state energy levels).

Based on previous electronic band assignments made for poly[Ni(salen)] [1,4] and considering that electronic bands with the same Abs versus $E$ profiles are associated with the same charge carriers, we propose the following band assignment for the two copper polymers: (i) the electronic bands at $\lambda_{\max }<320 \mathrm{~nm}(>3.88 \mathrm{eV})$ are assigned to the intervalence band, $W_{\mathrm{I}}$, since they decrease in intensity upon oxidation; (ii) the bands at $\lambda=364-360 \mathrm{~nm}(3.41-3.44 \mathrm{eV})$ to the transition between the valence and antibonding polaron level, $W_{2}$, and the bands at $\lambda=966-945 \mathrm{~nm}(1.28-1.31 \mathrm{eV})$ to the transition between the valence band to the bonding polaron level, $W_{1}$. The very intense band at $\lambda=484-486 \mathrm{~nm}(2.56-2.55 \mathrm{eV})$ behaves differently to all the other bands in that it shifts to lower energies continuously during polymer oxidation and also because its Abs versus $E$ transition is delayed to more positive potentials when compared to the other bands. Thus, this band does not correspond to $W_{3}$, but as was the case for the nickel polymers, may be due to charge transfer between the metal and the highly delocalised $\pi$ system formed (upon oxidation) through the quinoid bond between the two phenyl rings [4]; therefore, no electronic band could be directly assigned to the transition between polaronic levels, $W_{3}$.

A check for this electronic band assignment and estimation for the unobserved $W_{3}$ transition energy can be made by applying the expressions referred above. Assuming a plausible value of $265 \mathrm{~nm}(4.68 \mathrm{eV})$ for $W_{\mathrm{I}}$ for both polymers, $W_{1}\left(=W_{\mathrm{I}}-W_{2}\right)$ can be estimated as $1004 \mathrm{~nm}(1.23 \mathrm{eV})$ for poly[Cu(salen)] and $974 \mathrm{~nm}(1.27 \mathrm{eV})$ for poly[Cu(saltMe)]. This compares favourably with the corresponding experimental values, 1000 and $966 \mathrm{~nm}$. Moreover, $W_{3}\left(=W_{2}-W_{1}\right)$ for both polymers can be estimated by using the experimental $W_{1}$ and $W_{2}$ values: $563(2.20 \mathrm{eV})$ and $583 \mathrm{~nm}(2.13 \mathrm{eV})$ for poly $[\mathrm{Cu}($ salen $)]$ and poly $[\mathrm{Cu}($ saltMe $)]$, respectively. The calculated $W_{3}$ values are in the same region of the very intense CT band, which accounts for our inability to observe them in the electronic spectra of the oxidised polymers.

In Fig. 8, the energies of the band gap and the related electronic transitions are depicted for both $\mathrm{Cu}$ and $\mathrm{Ni}$ polymers, for comparison. As can be checked, the band gap is larger for the $\mathrm{Cu}$ polymers, but the difference between the states within the band gap is smaller when compared to those values of Ni polymers. The most important and straightforward conclusion is that the change in the metal leads to a more significant alteration in the electronic structure of the semi-conductor polymer than the introduction of different substituents in the ligand. Moreover, additional information can be gathered from the decrease in the band gap on going from $\mathrm{Cu}$ to $\mathrm{Ni}$. The increase in the number of charge carriers and higher stabilization of the corresponding doped state [31] are consistent with the higher electrochemical stability

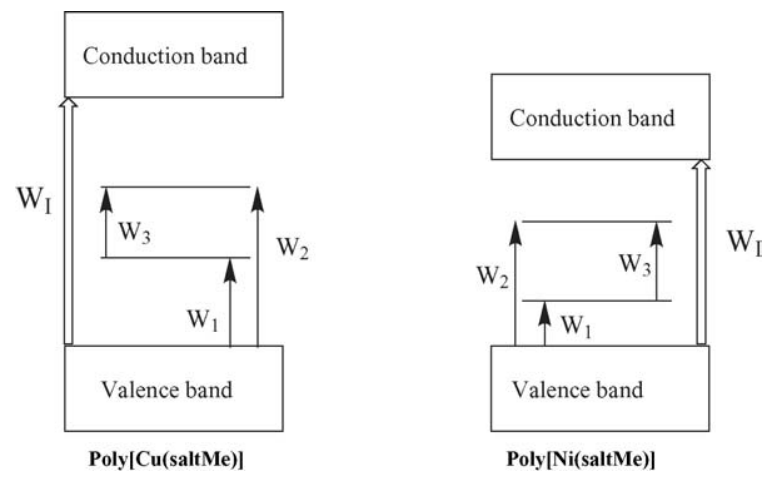

Fig. 8. Scheme of electronic structure of poly[Cu(saltMe) $]$ and poly[Ni(saltMe)] in the oxidised state; poly[Cu(saltMe)]: $W_{\mathrm{I}}=4.68$; $W_{1}=1.27 ; W_{2}=3.4$ and $W_{3}=2.13 \mathrm{eV}$ and (b) poly[Ni(saltMe) $]: W_{\mathrm{I}}=3.88$; $W_{1}=0.69 ; W_{2}=3.07$ and $W_{3}=2.79 \mathrm{eV}$ (data for Ni polymer was taken from reference [4]).

and conductivity in $\mathrm{CH}_{3} \mathrm{CN}$ solution shown by the nickel polymers.

\section{Conclusions}

By using electrochemical techniques coupled to spectroscopic techniques (in situ UV-vis and ex situ EPR) and by comparison with data for the analogous nickel polymers, we were able to show that oxidative polymerisation of copper salen-based monomers, $[\mathrm{Cu}($ salen $)]$ and $[\mathrm{Cu}($ saltMe $)]$, and redox switching of the corresponding polymers are ultimately ligand-based processes. As for their nickel analogs, copper polymers behave as delocalised ('conducting'), rather than discrete site ('redox') polymers, with the salen ligands being critical in defining the electroactive sites. The main charge carriers were then identified as polarons, allowing the electronic bands in the oxidised polymer to be assigned using the polaronic model.

The electronic structure of the semi-conductor films, the band gap values and the energies of the related electronic states were significantly influenced by the change of metal centre. This opens a new strategy for the synthesis of $[\mathrm{M}($ salen $)]$-based polymers with specific properties, as appropriate choice of metal can be used to fine tune the film electronic properties. In pursuit of this, palladium and platinum salen-based polymers are being prepared and characterised in order to extend and exploit these studies to second and third row transition metals.

\section{Experimental section}

\subsection{Materials}

Ethylenediamine and salicylaldehyde were used as received from Merck, and 2,3-diamine-2,3-dimethylbutane was prepared from the reduction of 2,3-dimethyl-2,3- 
dinitrobutane (Aldrich) as described in the literature [32]. Acetonitrile (Fisons, HPLC grade) was refluxed twice over $\mathrm{CaH}_{2}$ and distilled under Ar before use. Tetraethylammonium perchlorate (TEAP; Fluka, puriss) was used as received and tetra- $n$-buthylammonium perchlorate (TBAP) was prepared from tetra- $n$-buthylammonium bromide (Aldrich) and perchloric acid (Merck, p.a.) and recrystallised from acetone (Merck, pro analysi) and water.

\subsection{Synthesis}

The ligands $N, N^{\prime}$-bis(salicylidene)ethane-1,2-diamine ( $\mathrm{H}_{2}$ salen) and 2,3-dimethyl- $N, N^{\prime}$-bis(salicylidene)butane2,3-diamine $\left(\mathrm{H}_{2}\right.$ saltMe) were prepared from salicylaldehyde (Merck) and the corresponding diamine as described in the literature [32]. Copper(II) complexes were prepared by refluxing ethanolic solutions of copper(II) acetate monohydrate (Merck) with the corresponding Schiff base, recrystallised from acetonitrile and dried by continuous pumping for several hours [33].

\subsection{Electrochemistry}

Cyclic voltammetry was performed with an Autolab PGSTAT 20 potentiostat/galvanostat. The electrochemical cell was a closed standard three-electrode cell that was connected to a solution reservoir through a Teflon tube. A Pt disk electrode with an area of $0.0314 \mathrm{~cm}^{2}$ was used as working electrode and a $\mathrm{Pt}$ gauze as the counter electrode. The potentials refer to an $\mathrm{Ag} / \mathrm{AgCl}\left(1 \mathrm{~mol} \mathrm{dm}^{-3} \mathrm{NaCl}\right)$ reference electrode. Prior to use, the working electrode was polished with an aqueous suspension of $0.05 \mu \mathrm{m}$ alumina (Buehler) on a Master-Tex (Buehler) polishing pad, then rinsed with water and acetone and dried in an oven. All solutions were deaerated and delivered to the cell by a stream of Ar.

\subsection{UV-vis transmission spectroscopy}

The spectrometers used were either a Hewlett Packard HP8451 or a Perkin Elmer Lambda 19 UV/VIS/NIR. Spectroscopic measurements were made in situ in transmission mode, with the electrode under potential control, using an Autolab PGSTAT20 potentiostat/galvanostat. The working electrode was an indium tin oxide-coated conducting glass (ITO, Balzers) and its area (typically $2.0 \mathrm{~cm}^{2}$ ) was defined by a silicone sealant (Dow Corning 3145 RTV). All potentials were measured and quoted with respect to a $\mathrm{Hg} / \mathrm{HgCl}_{2}$ ( $\mathrm{KCl}$ sat.) reference electrode; the counter electrode was Pt gauze. The Hewlett Packard HP8451A spectrophotometer was programmed to acquire spectra at $10 \mathrm{~s}$ intervals in the range $300-820 \mathrm{~nm}$ during potential sweeping, while the Perkin Elmer spectrometer was programmed to acquire spectra in the range $300-1600 \mathrm{~nm}$ at fixed potentials, incrementally stepped in $0.1 \mathrm{~V}$ intervals from 0 to $1.5 \mathrm{~V}$ and back to $0 \mathrm{~V}$. A background spectrum in $0.1 \mathrm{~mol} \mathrm{dm}^{-3} \mathrm{TEAP} / \mathrm{CH}_{3} \mathrm{CN}$ and a reference spectrum in $1 \mathrm{mmol} \mathrm{dm}^{-3}[\mathrm{Cu}($ salen $)]$ and
$[\mathrm{Cu}$ (saltMe) $]$ in $0.1 \mathrm{~mol} \mathrm{dm}{ }^{-3}$ TEAP or TBAP/CH${ }_{3} \mathrm{CN}$ were collected prior to electrode modification.

\subsection{Electron paramagnetic resonance}

EPR spectra were obtained with an X-band Bruker ESP $300 \mathrm{E}$ spectrometer at room temperature and $77 \mathrm{~K}$. Spectra were calibrated with diphenylpricrylhydrazyl (dpph; $g=2.0037$ ) and the magnetic field was calibrated by use of $\mathrm{Mn}(\mathrm{II})$ in $\mathrm{MgO}$. The samples were prepared as poly[Cu(salen)], poly[Cu(saltMe) $]$ or nickel/copper polymer-modified $\mathrm{Pt}$ wires $(\phi=0.025 \mathrm{~cm})$ that were inserted into quartz EPR tubes $(\phi=0.4 \mathrm{~cm})$.

\subsection{Procedures}

Copper-based polymers were deposited by cycling the potential of the working electrode immersed in a $\mathrm{CH}_{3} \mathrm{CN}$ solution containing $1 \mathrm{mmoldm}^{-3}$ copper monomer and $0.1 \mathrm{~mol} \mathrm{dm}^{-3}$ TEAP or TBAP, between 0.0 and 1.5 at $0.1 \mathrm{~V} \mathrm{~s}^{-1}$. Films of different thickness were prepared by using different numbers of potential cycles; a coulometric assay in monomer-free solution for each film yielded the resultant electroactive surface concentration, $\Gamma\left(\mathrm{mol} \mathrm{cm}{ }^{-2}\right)$, using $n$ values (doping level) calculated from coulometric data. The voltammograms used in the calculation of the electroactive surface concentration were performed at $0.010 \mathrm{~V} \mathrm{~s}^{-1}$ to ensure that the film oxidation/reduction processes occur throughout the whole film. After electropolymerisation, the modified electrode was thoroughly rinsed with dry $\mathrm{CH}_{3} \mathrm{CN}$ and all the electrochemical characterisation experiments were carried out on films immersed in $0.1 \mathrm{~mol} \mathrm{dm}{ }^{-3} \mathrm{TEAP} / \mathrm{CH}_{3} \mathrm{CN}$. Films were cycled between 0.0 and $1.5 \mathrm{~V}$ at scan rates in the range $0.020-2.0 \mathrm{~V} \mathrm{~s}^{-1}$.

Copper-based films for UV-vis were deposited by cycling the potential of the working electrode between 0.0 and $1.5 \mathrm{~V}$ of a $\mathrm{CH} 3 \mathrm{CN}$ solution $1 \mathrm{mmol} \mathrm{dm}^{-3}$ in copper monomer and $0.1 \mathrm{~mol} \mathrm{dm}^{-3}$ TBAP; scan rates were $0.01 \mathrm{~V} \mathrm{~s}^{-1}$ for UV-vis studies. After electropolymerisation, the modified electrode was rinsed thoroughly with dry $\mathrm{CH}_{3} \mathrm{CN}$ and the experiments were carried out on films immersed in $0.1 \mathrm{~mol} \mathrm{dm}^{-3} \mathrm{TBAP} / \mathrm{CH}_{3} \mathrm{CN}$.

Copper homopolymers and copper/nickel copolymers for EPR studies were prepared by potential controlled electrolysis at 1.3 or $1.5 \mathrm{~V}$ for $10 \mathrm{~min}$ (oxidised states). After preparation the films were immediately inserted in EPR tubes.

\section{Acknowledgements}

We thank the British Council/CRUP Joint Research Programme (B-6/03), Fundação para a Ciência e a Tecnologia (FCT), Portugal (project POCT/32831/QUI/2000) and the EPSRC (GR/N00968) for financial support. MM thanks the FCT for a fellowship. 


\section{Appendix A. Supplementary data}

Supplementary data associated with this article can be found, in the online version, at doi:10.1016/j.electacta. 2005.04.026.

\section{References}

[1] M. Vilas-Boas, C. Freire, B. de Castro, P.A. Christensen, A.R. Hillman, Inorg. Chem. 36 (1997) 4919.

[2] M. VilasBoas, C. Freire, B. de Castro, A.R. Hillman, J. Phys. Chem. B 102 (1998) 8533.

[3] M. Vilas-Boas, M.J. Henderson, C. Freire, A.R. Hillman, E. Vieil, Chem. Eur. J. 6 (2000) 1160.

[4] M. Vilas-Boas, C. Freire, B. de Castro, P.A. Christensen, A.R. Hillman, Chem. Eur. J. 7 (2001) 139.

[5] M. Vilas-Boas, J. Henderson, C. Freire, A.R. Hillman, E. Vieil, Langmuir 19 (2003) 7460.

[6] P.-H. Aubert, P. Audebert, M. Roche, P. Capdevielle, M. Maumy, G. Ricart, Chem. Mater. 13 (2001) 2223.

[7] J. Losada, I. del Peso, L. Beyer, Inorg. Chim. Acta 321 (2001) 107.

[8] J.L. Reddinger, J.R. Reynolds, Chem. Mater. 10 (1998) 1236.

[9] P. Audebert, P. Capdevielle, M. Maumy, New J. Chem. 16 (1992) 697.

[10] P. Audebert, P. Capdevielle, M. Maumy, New J. Chem. 15 (1991) 235.

[11] M.E.G. Lyons, in: M.E.G. Lyons (Ed.), Electroactive Polymer Electrochemistry, Part 1: Methods and Applications, Plenum Press, New York, 1994 (Chapter 1).

[12] C.E. Dahm, D.G. Peters, J. Simonet, J. Electroanal. Chem. 410 (1996) 163.

[13] M. Vilas Boas, C. Freire, A.R. Hillman, unpublished results.

[14] F. Daire, F. Bedioui, J. Devynck, C. Bied-Charreton, J. Electroanal. Chem. 224 (1987) 95.
[15] C. Armengaud, P. Moisy, F. Bedioui, J. Devynck, C. Bied-Charreton, J. Electroanal. Chem. 277 (1990) 197.

[16] D.M. Kelly, J.G. Vos, in: M.E.G. Lyons (Ed.), Electroactive Polymer Electrochemistry, Part 2: Methods and Applications, Plenum Press, New York, 1994 (Chapter 8).

[17] F. Bedioui, M. Voisin, J. Devynck, C. Bied-Charreton, J. Electroanal. Chem. 297 (1991) 257.

[18] C.R. Martin, I. Rubinstein, A.J. Bard, J. Am. Chem. Soc. 104 (1982) 4817.

[19] P.N. Bartlett, Biosensors: Fundamentals and Applications, Oxford University Press, Oxford, 1987 (Chapter 13).

[20] A. Sevcik, Czech. Chem. Commun. 20 (1948) 327.

[21] P. Daum, R. Murray, J. Phys. Chem. 85 (1981) 389.

[22] P. Daum, J.R. Lenhard, D. Rolison, R. Murray, J. Am. Chem. Soc. 102 (1980) 4649

[23] N. Oyama, T. Osaka, in: R.W. Murray (Ed.), Molecular Design of Electrode Surface, Wiley, New York, 1992 (Chapter 8).

[24] A.B.P. Lever, Inorganic Electronic Spectroscopy, Elsevier, New York, 1984.

[25] G. Maki, J. Chem. Phys. 29 (1958) 1129.

[26] S.M. Dale, A. Glidle, A.R. Hillman, J. Mater. Chem. 2 (1992) 99.

[27] (a) A.H. Maki, B.R. McGarvey, J. Chem. Phys. 29 (1958) 31;

(b) A.H. Maki, B.R. McGarvey, J. Chem. Phys. 29 (1958) 35

[28] (a) Y. Nishida, K. Hayashida, A. Sumita, S. Kida, Inorg. Chim. Acta 31 (1978) 19;

(b) Y. Nishida, S. Kida, Coord. Chem. Rev. 27 (1978) 273;

(c) Y. Nishida, K. Hayashida, S. Kida, J. Coord. Chem. 10 (1980) 101

[29] F. Thomas, O. Jarjayes, C. Duboc, C. Philouze, E. Saint-Aman, J.-L. Pierre, Dalton Trans. (2004) 2662.

[30] J. Bredas, in: T.J. Skotheim (Ed.), Handbook of Conducting Polymers, Marcel Dekker, New York, 1986 (Chapter 25).

[31] J. Roncali, Chem. Rev. 97 (1997) 173.

[32] D. Chen, A. Martel, Inorg. Chem. 26 (1987) 1026.

[33] C. Freire, B. Castro, J. Chem. Soc. Dalton Trans. (1998) 1491. 